\title{
Fecal androgen levels in common marmoset (Callithrix jacchus) males living in captive family groups
}

D.C. Castro and M.B.C. Sousa

\author{
Departamento de Fisiologia, Universidade Federal do Rio Grande do Norte, \\ Natal, RN, Brasil
}

\begin{abstract}
Correspondence
M.B.C. Sousa

Departamento de Fisiologia, UFRN

Caixa Postal 1511

59078-970 Natal, RN

Brazil

Fax: +55-84-211-9206

E-mail: mdesousa@cb.ufrn.br

Research supported by $\mathrm{CNPq}$

(Nos. 301.309/84-1 and

521186/97) to M.B.C. Sousa.
\end{abstract}

Received March 19, 2004

Accepted October 13, 2004

\begin{abstract}
In captive common marmoset groups, the reproductive inhibition observed in subordinate female seems to be a result of olfactory, visual and behavioral cues from the dominant female. However, few studies have examined the relationship among adult males living in the same social group. These studies have shown that reproductive failure among peer males seems to be based on hormonal and behavioral mechanisms. New insights on sexual strategies in primates have been shown using fecal steroids, but so far no information is available for common marmoset males. In the present study, we evaluated the influence of light-dark cycle, age and reproductive condition on the profile of fecal androgens in males living in the same family group. Feces were collected from six fathers and six sons for androgen determination during the light phase of the 24-h cycle for eight days randomly distributed over a 4-week period. Androgen levels were determined by enzyme immunoassay technique. Adult sons showed higher androgen levels $(166.97 \pm 22.95 \mathrm{ng} / \mathrm{g})$ than fathers $(80.69 \pm$ $44.38 \mathrm{ng} / \mathrm{g}$ ) and juveniles $(49.06 \pm 23.15 \mathrm{ng} / \mathrm{g} ; \mathrm{P}<0.05)$. No diurnal variation $(\mathrm{P}>0.05)$ in fecal androgen profile was observed in adults or juveniles. No indication of androgen-mediated social competition between fathers and adult sons was demonstrable. These results provide basic information on fecal androgen profile useful to investigate the socioendocrinology of free-ranging common marmoset males and verify that, in contrast to daughters, the reproductive suppression of sons is not based on physiological inhibition of their gonads.
\end{abstract}

\section{Introduction}

Reproductive inhibition among females of the same social group is a common characteristic of species of the callithrichid family of New World primates (Callithrixjacchus $(1,2)$, Saguinus oedipus $(3,4)$, and S. fuscicollis (5)). In common marmosets, this inhibition seems to be a result of olfactory, visual
Key words

- Common marmosets

- Fecal androgens

- Male sexual strategies

- Circadian variation

- Reproductive suppression and behavioral cues from dominant females toward subordinates. The mechanisms of sensory mediation of ovulation inhibition of subordinate females remain to be demonstrated (6). Due to intense reproductive competition in the species, the dominance relationship among females has been very well studied. However, documentation about escape from inhibition by subordinate calli- 
thrichid females in laboratory groups (among mothers and daughters or among unrelated females) has shown that reproductive inhibition is not as stringent as thought (7-11). The escape from inhibition by subordinate females (daughters) was also recorded in a monogamous wild group of common marmosets (12).

On the other hand, few studies have addressed the role of sex hormones in male behavior among captive marmosets, with only a few papers examining the sexual strategies used by males to maintain social rank and reproductive position within the social group (7,13-15).

As suggested by Abbott et al. (6), common marmoset females may occupy a position between plural and singular reproductive strategies within the eusociality continuum since subordinate females show behavioral polyethism besides adrenocortical and metabolic differences. In this case, dominant females are more engaged in sexual and affiliative behavior with the reproductive male and have a higher reproductive rate, high cortisol levels and a more efficient mechanism to metabolize glucose than subordinates.

Studying subordinate common marmoset males living in peer groups, Abbott (7) observed that plasma testosterone concentration was significantly lower in only one subordinate male compared to dominants in six groups studied, although all dominant males showed a higher testosterone range than the subordinates. This investigator also reported that the dominants in other captive groups of unrelated adult males had significantly higher plasma luteinizing hormone and testosterone levels, indicating that reproductive failure in males seems to depend, at least in part, on hormonal differences (16). Despite this reproductive inhibition, subordinate males may show the mounting behavior and even ejaculate $(7,13)$. Baker et al. (15), investigating a mechanism to explain the reproductive collapse of sons living in their natal groups, found that avoidance of mating with familiar and related females and possibly behavioral mechanisms of competition were involved in the inhibition since testosterone levels were similar for fathers and sons. Thus, the mechanisms involved in reproductive inhibition among common marmoset males seem to be involved in hormonal changes among unrelated animals, but not between fathers and sons.

New insights into the sexual strategies of New World primates are emerging from studies conducted under free-ranging conditions using hormonal measurements in feces. For instance, in common marmosets, Albuquerque et al. (12) found that a subordinate female (probably a daughter), although showing ovarian inhibition most of the time, escaped from suppression at the end of the reproductive female's gestation period. However, no endocrinological data have been obtained thus far for wild males. It should be pointed out that before the use of these techniques it is necessary to establish if androgens can be detected in feces and if their profile of variation can be standardized taking into account diurnal variation and physiological variables such as age and social condition.

It is known from the literature that plasma androgens have a diurnal pattern of fluctuation in common marmosets (17), showing higher levels during the dark phase, which decrease from the beginning through the end of the light phase. This pattern is similar to that described for plasma testosterone in rhesus monkeys (Macaca mulatta) (18) and Japanese monkeys (Macaca fuscata yakui) (19). In contrast, no significant differences between the cortisol excreted in feces during the morning and afternoon periods were found for common marmoset males (20). This suggests that males may have different mechanisms underlying fecal excretion compared to females, which show significant higher levels of cortisol excreted in the afternoon (21). Also, this finding might be asso- 
ciated with lower basal cortisol levels in males than in females (22). Therefore, our aim in the present study was to obtain information about the profile of androgen excretion in feces and investigate if it is under the influence of the light/dark cycle, age and social rank in common marmoset males living in captivity in family groups.

\section{Material and Methods}

\section{Animals}

We selected six family groups of common marmosets, Callithrix jacchus, living at the Núcleo de Primatologia, a marmoset colony of Universidade Federal do Rio Grande do Norte, Northeastern of Brazil ( $5^{\circ} 50^{\prime} \mathrm{N}$ and $35^{\circ} 12^{\prime} \mathrm{W}$ ). Family groups had a reproductive male and female (all females were pregnant to standardize the reproductive condition) and one pair of twins of both sexes. In three groups the twins were adults and in the remaining three they were juveniles.

Each family group was living in an outdoor cage measuring $2 \times 2 \times 1 \mathrm{~m}(\mathrm{~N}=2) ; 2 \times$ $2 \times 3 \mathrm{~m}(\mathrm{~N}=2)$ or $4 \times 4 \times 2 \mathrm{~m}(\mathrm{~N}=4)$ depending on group size. For identification, each animal was painted with a distinctive mark on the body (tuft, tail, forelimb, or hind limb). As an outdoor colony, they were under natural climatic conditions with the light phase of the 24-h period occurring from approximately 5:00 to 17:00 h. They were in olfactory and auditory but not visual contact with animals of neighboring cages. Food was served twice a day, around 9:00 and 14:00 h, and water was offered ad libitum.

\section{Fecal collection}

The total period of fecal collection lasted seven months, from March, 1998 to September, 1999. We collected fecal matter from 12 animals, i.e., 6 reproductive (fathers) and 6 non-reproductive (3 adults and 3 juvenile sons) males. Samples were collected through- out the light phase twice a week for 4 weeks for each family group, for a total of 8 complete days for each animal. Feces were collected and stored as described by Sousa and Ziegler (21) until analysis for androgens by enzyme immunoassay.

\section{Hormone determination}

First we weighed $0.1 \mathrm{mg}$ of wet feces from each sample after homogenization using a spatula. Since all animals were fed the same basic diet and no occurrence of diarrhea was recorded, we assume that the water content of the feces was the same. Sample preparation of the fecal material was performed after sequential hydrolysis and solvolysis. An aliquot of $50 \mu 1$ of the alcoholic extract of the samples was used to run the enzyme immunoassay.

The antibody (R-156-7) and HRP (Testo:HRP), both prepared by C. Munro (University of California, Davis, CA, USA), were used at respective dilutions of 1:20 and $1: 40$.

The assay for common marmosets was validated on the basis of parallelism and accuracy. Mean accuracy was $110.63 \pm 5.7 \%$ $(\mathrm{N}=3)$ and the curve using serial dilutions of a fecal pool from common marmoset males was parallel to the testosterone standards $(\mathrm{t}=$ 4.38; $\mathrm{P}>0.05)$. The standards ranged from 2.5 to $500 \mathrm{pg} / \mathrm{ml}$ and the intra- and interassay coefficients of variation were 8.67 and $22.70 \%$, respectively $(\mathrm{N}=19)$.

The recovery of testosterone added to a fecal pool was always around $20 \%$ higher than the amount added, showing that other androgens were reacting to our testosterone antibody. As demonstrated (23), testosterone is almost absent in common marmoset feces and the main metabolite in this material is androsterone. Other androgens detected in marmoset feces by these investigators were androstenedione, dehydroepiandrosterone, dehydroandrosterone, and epiandrosterone. Thus, we are probably 
measuring testosterone metabolites, which in the present testosterone assay are reported as ng androgens per gram feces. The androgens of adrenal origin do not interfere with the results because, in common marmosets, the fetal adrenal zone regresses during the first week of life and the adrenal reticular zone is not present in older animals (24).

\section{Statistical analysis}

To perform the statistical analysis, since the number of fecal pellets was different for each male, we first averaged the hormonal data within a particular male before calculating the total average for each group. Data regarding diurnal variation in defecation pattern in males and the profile of androgen excretion were analyzed statistically by ANOVA for repeated measures, with the data divided into the following intervals: a) twelve 1-h intervals and b) six 2-h intervals (5:00-7:00, 7:00-9:00, 9:00-11:00, 11:0013:00, 13:00-15:00, and 15:00-17:00 h); c) three 4-h intervals (5:00-9:00, 9:00-13:00, and 13:00-17:00 h), and d) four 3-h intervals (5:00-8:00, 8:00-11:00, 11:00-14:00, and 14:00-17:00 h).

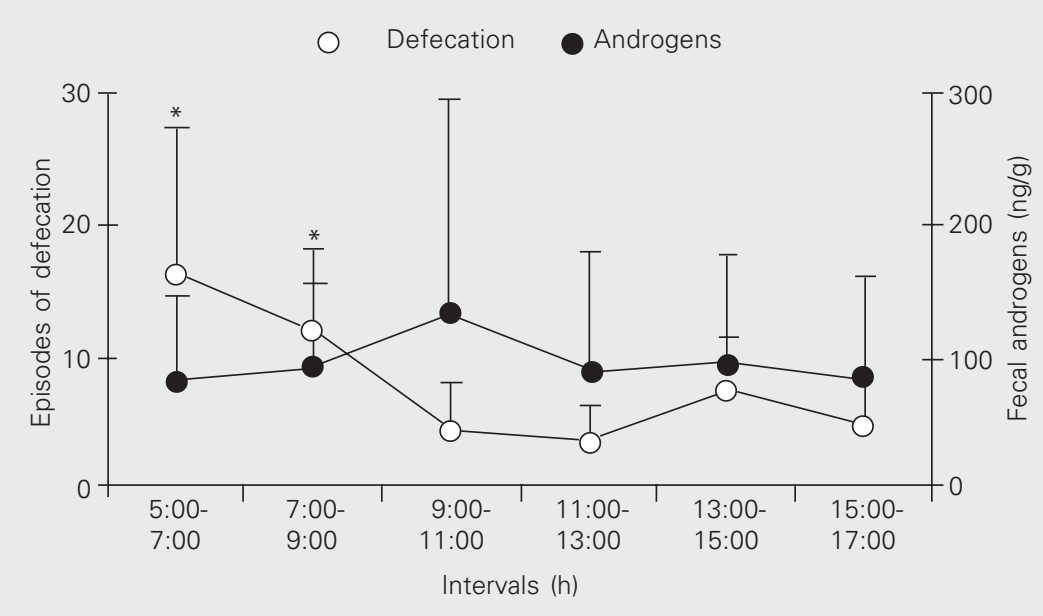

Figure 1. Mean defecation frequency in the six 2-h intervals during the natural light phase of the 24-h cycle for common marmoset males living in family groups in outdoor cages (open circles). Mean fecal androgens under the same conditions are given as filled circles. Data are reported as means \pm SEM for 12 marmoset males. ${ }^{*}$ The 5:00-7:00 and 7:00-9:00 intervals were significantly different from the others $(P<0.001$, ANOVA).
We also used the Student $t$-test to compare androgen levels between the following two conditions: a) period of the day - morning (5:00-11:00 h) vs afternoon (11:00-17:00 h); b) age - adult ( $N=9: 6$ fathers and 3 sons) $v s$ juvenile $(\mathrm{N}=3$ : sons) animals; c) reproductive condition - reproductive $(\mathrm{N}=6$ : fathers) $v s$ non-reproductive ( $\mathrm{N}=3$ : adult sons) animals; d) social competition - fathers of adult sons $(\mathrm{N}=3) v s$ fathers of juvenile sons $(\mathrm{N}=3)$. The level of significance was set at $\mathrm{P} \leq 0.05$ in both tests.

\section{Results}

We collected 615 samples from the 12 males (408 samples in the morning and 207 in the afternoon), varying in number between animals.

\section{Diurnal profile of defecation and fecal excretion of androgens}

The mean diurnal defecation pattern for common marmoset males is shown in Figure 1 (open circles). Males defecated more frequently during the two first 2-h intervals in the morning and the frequencies observed during these intervals (5:00-7:00 and 7:009:00 h) were significantly different from all remaining intervals $\left(\mathrm{F}_{(5,11)}=10.99, \mathrm{P}<0.001\right.$; ANOVA) but not from one another.

Figure 1 also shows the diurnal profile of fecal androgen excretion for each 2-h interval for all 12 animals, as illustrated by the filled circles. It can be seen that the concentration of fecal androgens increased during the third interval but this fluctuation was not significantly different among the six 2-h intervals along the light phase. Indeed, when the analysis of the data was split by age (adult and juveniles) no changes were detected in either group. This absence of variation was also observed when the data were grouped for each 1-h period $\left(\mathrm{F}_{(2,12)}=0.32, \mathrm{P}\right.$ $=0.891$; ANOVA), for four 3-h intervals $\left(\mathrm{F}_{(2,12)}=0.23, \mathrm{P}=0.871\right.$; ANOVA $)$ and for 
three 4-h intervals $\left(\mathrm{F}_{(2,12)}=0.17, \mathrm{P}=0.842\right.$; ANOVA). Again, no difference was found when the values obtained for androgens in the morning were compared with those obtained in the afternoon.

\section{Age and social competition versus excretion of fecal androgens}

Comparisons of mean fecal androgens excreted by adults $(109.45 \pm 56.78 \mathrm{ng} / \mathrm{g} ; \mathrm{N}=$ 9) and juveniles $(49.06 \pm 23.15 \mathrm{ng} / \mathrm{g} ; \mathrm{N}=3)$ did not show significant differences between groups $(\mathrm{t}=1.89, \mathrm{P}=0.111$; Student $t$-test $)$. However, when the adults were split into two groups of fathers and adult sons, statistical differences were detected in both comparisons, i.e., fathers and adult sons $(\mathrm{t}=$ 2.79; $\mathrm{P}=0.034)$ and adult and juvenile sons $(\mathrm{t}=3.17 ; \mathrm{P}=0.003)$. Also, a positive correlation was found between mean androgen levels and age considering adult and juvenile sons $(\mathrm{r}=0.697$; $\mathrm{P}<0.05$; Figure $2 \mathrm{~A})$.

No significant difference was detected $(\mathrm{t}$ $=1.47 ; \mathrm{P}=0.464$ ) when the androgen values for fathers who were living with adult sons $(95.86 \pm 62.44 \mathrm{ng} / \mathrm{g} ; \mathrm{N}=3)$ in family groups were compared to those of fathers living with juveniles $(65.53 \pm 18.34 \mathrm{ng} / \mathrm{g}$; $\mathrm{N}=3$; Figure 2B).

\section{Discussion}

Common marmoset males showed the same pattern of defecation as females (21), indicating that feces should be collected from marmosets at the beginning of the light phase of the 24-h cycle.

In the present study, no difference in the pattern of fecal androgen excretion was observed during the light phase. In contrast, Kholkute (17) demonstrated diurnal variation in plasma androgens in common marmosets. The absence of correlation between plasma and fecal androgens might be occurring because plasma androgens might be fluctuating in common marmosets, as also observed for plasma luteinizing hormone, prolactin and cortisol in rats whose profiles of variation showed, besides a circadian rhythm, a simultaneous semicircadian and ultradian rhythm. This means that a single period may contain various period components (25). Thus, fecal androgen profiles may be fluctuating with different periodicities and the final rhythm may not be detected in feces. Additionally, we can also assume that the absence of fluctuations in the final androgen profile may be due to a reversed pattern of the various androgens measured (e.g., testosterone metabolites such as androsterone, dehydroepiandrosterone and epiandrosterone), thus preventing the detection of any changes. Although testosterone and DHT increased significantly in urine of cotton-top tamarins after intramuscular injection of testosterone (26), for common marmosets testosterone does not differ in feces from intact and castrated males (23). According to these investigators, testosterone metabolism is complex in primates and part of the problem of discriminating gonadal status in males is that there are individual differences in androgen excretion between species and between individuals of the same species. Among the factors that are known to potentially affect testosterone out-
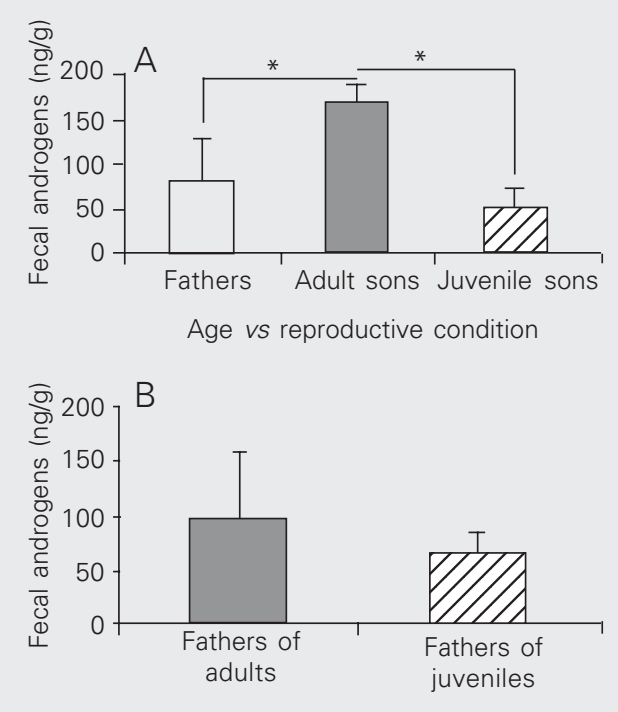

Figure 2. A, Fecal androgen levels for adult reproductive males (fathers, $N=6$ ) and non-reproductive males (adult sons, $\mathrm{N}=$ 3; juvenile sons, $N=3$ ). Data are reported as means \pm SEM. ${ }^{*} \mathrm{P}<$ 0.05 for adult sons $v s$ fathers and adult vs juvenile sons (Student $t$-test). $B$, Fecal androgen levels for fathers according to the age of the sons, i.e., fathers living with adult sons $(\mathrm{N}=3)$ and fathers living with juvenile sons $(N=3)$. Data are reported as means \pm SEM. The fathers did not differ in fecal androgen excretion (Student $t$-test). 
put, they pointed out the diet, health, diurnal variation, and environmental and social stress.

Gender differences may be also associated with fecal excretion of steroids in common marmosets, since Raminelli et al. (20) did not find significant differences between morning and afternoon cortisol levels in adult common marmoset males, contrary to the results obtained for common marmoset females.

Our results showed that androgen levels excreted by adult and juvenile common marmoset males were similar to those found in plasma $(27,28)$, being about $50 \%$ lower in juveniles. Adult sons presented significantly higher basal androgen levels than juveniles and also than their fathers but no differences in androgen levels were found between fathers living with adult and juvenile sons. This absence of differences could be due to the small sample size $(\mathrm{N}=3)$.

Since sons are considered to be subordinate in relation to their fathers (7), we expected hormonal differences to be found between fathers and sons, with fathers showing higher androgen levels than their adult sons. However, we found that adult sons showed significantly higher fecal androgen excretion than fathers living in the same family group, suggesting that sons might be more aroused to mate. The reason why sons produce higher levels of androgens than their fathers might be that common marmoset males are able to detect the reproductive condition of females by olfactory cues, as suggested by Smith and Abbott (29) and Ferris et al. (30). In a recent study, Ferris et al. (31), using functional magnetic resonance imaging, have shown additionally that the periovulatory odors of females significantly increased the positive signal in several central nervous system areas that represent a common circuit for sexual arousal and motivation. It has also been proposed that, as demonstrated for C. pygmaea (32), pregnancy is probably signaled in common mar- mosets (33). These investigators observed that huddling and proximity behaviors increase between reproductive pairs when conception occurs. In the present study, since all fathers were paired with pregnant females, the parental investment of males may have been redirected to other activities associated with reproductive success such as predator defense and mate guarding behavior, among others.

Social status among related common marmoset males seems not to be established and maintained by agonistic behavior since no data are available showing overt fighting among them, particularly between fathers and sons (15). Agonistic behavior during competition is usually induced by physiological changes and dominant males have been found to show higher testosterone levels than subordinate ones in both Old and New World monkeys (Papio anubis, 34; Saimiri sciureus, 35). However, this does not occur in all primates and this assumption remains to be clarified. For common marmosets, the basal androgen levels of fathers might be more under the control of the physiological condition of the reproductive female than of the age of the sons and this assumption is reinforced by the finding showing no difference in androgen levels between fathers living with adult and juvenile sons.

In contrast, adult sons might require elevated basal androgen levels to increase the probability to inseminate females since, under natural living conditions, mating for subordinate males usually occurs in an opportunistic context (36). Castro (37) and LazaroPerea (38) recorded encounters between neighboring wild groups of common marmosets and observed that only non-reproductive males were seen copulating with females of those groups. Thus, this could be the major reason explaining the higher androgen levels of non-reproductive common marmoset males when living in their natal group.

Finally, it is important to point out that 
we demonstrated that fecal androgen profile in common marmoset males did not change during light-dark cycle and seems to be influenced by reproductive conditions. This information is critical to establish a basic frame to start fecal collection, thus allowing the study of socioendocrinology in animals living in free-ranging groups. The studies conducted so far on physiological and hormonal correlates of the reproductive behavior of females have provided a clearer picture for their sexual strategies than for males.
Therefore, it is expected that more data on the reproductive strategies of common marmoset males will become readily available.

\section{Acknowledgments}

We would like to thank Dr. Toni E. Ziegler for valuable help with the manuscript. We also thank Antonio B. Silva, Geniberto C. Santos and Ednólia Camara for their help with colony management, and Flavio J.V. Coutinho for veterinary care.

\section{References}

1. Abbott DH, McNeilly AS, Lunn SF, Hulme MJ \& Burden JF (1981), Inhibition of ovarian function in subordinate female marmoset monkeys (Callithrix jacchus). Journal of Reproduction and Fertility, 63: 335-345.

2. Hearn JP (1983). The common marmoset (Callithrix jacchus). In: Hearn JP (Editor), Reproduction in New World Primates. Kluver Boston Inc., Hingham, MA, USA, 181-215.

3. French JA, Abbott DH \& Snowdon CT (1984). The effect of social environment on estrogen excretion, scent marking, and sociosexual behavior in tamarins (Saguinus oedipus). American Journal of Primatology, 6: 155-167.

4. Ziegler TE, Savage A, Scheffler G \& Snowdon CT (1987). The endocrinology of puberty and reproductive functioning in female cottontop tamarins (Saguinus oedipus) under varying social conditions. Biology of Reproduction, 37: 618-627.

5. Epple G \& Katz Y (1984). Social influences on estrogen excretion and ovarian cyclicity in saddleback tamarins (Saguinus fuscicollis). American Journal of Primatology, 6: 215-228.

6. Abbott DH, Saltzman W, Schultz-Darken NJ \& Tannenbaum PL (1998). Adaptations to subordinate status in female marmoset monkeys. Comparative Biochemistry and Physiology, C119: 261-274.

7. Abbott DH (1984). Behavioral and physiological suppression of fertility in subordinate marmoset monkeys. American Journal of Primatology, 6: 169-186.

8. French JA \& Stribley JA (1987). Synchronization of ovarian cycles within and between social groups in golden lion tamarins (Leontopithecus rosalia). American Journal of Primatology, 12: 469478.

9. Heistermann M, Kleis E, Prove E \& Wolters H (1989). Fertility status, dominance, and scent marking behavior of family-housed female cotton-top tamarins (S. oedipus) in absence of their mothers. American Journal of Primatology, 18: 177-189.

10. Saltzman W, Schultz-Darken NJ \& Abbott DH (1997). Familial influences on ovulation function in common marmosets (Callithrix jacchus). American Journal of Primatology, 41: 159-177.

11. Ziegler TE \& Sousa MBC (2002). Parent-daughter relationship in common marmoset (Callithrix jacchus). Hormones and Behavior, 42: 356-367.

12. Albuquerque ACSR, Sousa MBC, Santos HM \& Ziegler TE (2001).
Behavioral and hormonal analysis of social relationship between oldest females in a wild monogamous group of common marmoset, Callithrix jacchus. International Journal of Primatology, 22: 631-645.

13. Anzenberger $G$ (1985). How stranger encounters of common marmosets (Callithrix jacchus jacchus) are influenced by family members: the quality of behavior. Folia Primatologica, 45: 204-224.

14. French JA \& Schaffner CM (1995). Social and developmental influences on urinary testosterone levels in male black tufted-ear marmoset (Callithrix kuhli). American Journal of Primatology, 36: 123 (Abstract).

15. Baker JV, Abbott DH \& Saltzman W (1999). Social determinants of reproductive failure in male common marmosets housed with natal family. Animal Behaviour, 58: 501-511.

16. Abbott DH (1993). Social conflict and reproductive suppression in marmosets and tamarin monkeys. In: Mason WA \& Mendoza SP (Editors), Primates Social Conflict. State University of New York Press, Albany, NY, USA, 331-372.

17. Kholkute SD (1984). Diurnal and annual variation in plasma androgen levels in the adult male marmoset (Callithrix jacchus). International Journal of Andrology, 7: 431-438.

18. Rose RM, Gordon TP \& Bernstein IS (1978). Diurnal variations in plasma testosterone and cortisol in rhesus monkeys living in social groups. Journal of Endocrinology, 76: 67-74.

19. Enomoto $T$ (1980). Diurnal variations in plasma testosterone and cortisol in the male Japanese monkey. Journal of the Anthropological Society of Nippon, 88: 285-288.

20. Raminelli JLF, Sousa MBC, Cunha MS \& Barbosa MFV (2001). Morning and afternoon patterns of fecal excretion of cortisol among reproductive and non-reproductive male and female common marmosets, Callithrix jacchus. Biological Rhythm Research, 32: 159167.

21. Sousa MBC \& Ziegler TE (1998). Diurnal variation in the excretion patterns of steroids in common marmoset (Callithrix jacchus) females. American Journal of Primatology, 46: 105-117.

22. Johnson EO, Kamilaris TC, Carter CS, Calogero AE, Gold PW \& Chrousos GP (1996). The behavioral consequences of psychogenic stress in a small, social primate (Callithrix jacchus jacchus). Biological Psychiatry, 40: 317-337.

23. Möhle U, Heistermann M, Palme R \& Hodges JK (2002). Character- 
ization of urinary and fecal metabolites of testosterone and their measurement for assessing gonadal endocrine function in male nonhuman primates. General and Comparative Endocrinology, 129: 135-145.

24. Levine J, Wolfe LG, Schiebinger RJ, Loriaux DL \& Cutler Jr GB (1982). Rapid regression of fetal adrenal zone and absence of adrenal reticular zone in the marmoset. Endocrinology, 111: 1797-1802.

25. Lewy H, Hans E, Naor Z \& Assikendazi IE (1998). Multifrequency time structure in $\mathrm{LH}$, prolactin and cortisol plasma concentrations. In: Touitou Y (Editor), Biological Clocks. Mechanisms and Applications. Elsevier Science, Amsterdam, The Netherlands, 431-434.

26. Ziegler TE, Carlson AA, Ginther AJ \& Snowdon CT (2000). Gonadal source of testosterone metabolites in urine of male cotton-top tamarin monkeys (Saguinus oedipus). General and Comparative Endocrinology, 11: 332-343.

27. Abbott DH (1978). The physical, hormonal and behavioural development of the common marmoset, Callithrix jacchus jacchus. In: Rothe H, Wolter HJ \& Hearn JP (Editors), Biology and Behaviour of Marmosets. Eigenverlag, Göttingen, Germany, 99-106.

28. Abbott DH \& Hearn JP (1978). Sexual development in the marmoset monkey, Callithrix jacchus: Aspects of physical, hormonal and behavioural development. Journal of Reproduction and Fertility, 53: 155-166.

29. Smith TE \& Abbott DH (1998). Behavioral discrimination between circumgenital odor from peri-ovulatory dominant and anovulatory female common marmosets (Callithrix jacchus). American Journal of Primatology, 46: 265-284.

30. Ferris CF, Snowdon CT, King JA et al. (2001). Functional imaging of brain activity in conscious monkeys responding to sexually arousing cues. NeuroReport, 12: 2231-2236.

31. Ferris CF, Snowdon CT, King JA et al. (2004). Activation of neural pathways associated with sexual arousal in non-human primates. Journal of Magnetic Resonance Imaging, 19: 168-175.

32. Converse LJ, Carlson AA, Ziegler TE \& Snowdon CT (1995). Communication of ovulatory state to mates by female pygmy marmosets (Cebuella pygmaea). Animal Behaviour, 49: 615-621.

33. Sousa MBC, Silva HPA, Albuquerque ACSR, Teixeira ICD, Raulino FC \& Oliveira AL (1997). Resposta reprodutiva de fêmeas de Callithrix jacchus a pareamentos sucessivos: repensando o "mate guarding" e o "pair-bond". In: Sousa MBC \& Menezes AAL (Editors), A Primatologia no Brasil. Vol. 6. Editora Universitária, Natal, $\mathrm{RN}$, Brazil, 91-108 (in Portuguese)

34. Sapolsky MR (1982). The endocrine-stress response and social status in the wild baboon. Hormones and Behavior, 15: 279-285.

35. Coe CL, Mendoza SP \& Levine S (1979). Social-status constrains the stress response in the squirrel-monkey. Physiology and Behavior, 23: 633-638.

36. Araújo A (1996). Influence des facteurs écologiques, comportementaux et démographiques sur la dispersion de Callithrix jacchus. PhD thesis, Université de Paris-Nord, Paris, France.

37. Castro CSS (1998). Dieta, padrão de uso do espaço e interações agressivas entre grupos de sagüi do Nordeste, Callithrix jacchus (Primates: Callithrichidae). PhD thesis, Universidade Federal de São Carlos, São Carlos, SP, Brazil, 117.

38. Lazaro-Perea C (2001). Intergroup interactions in wild common marmosets, Callithrix jacchus: territorial defence and assessment of neighbours. Animal Behaviour, 62: 11-21. 